\title{
Relations between age at occupational exposure to ionising radiation and cancer risk
}

\author{
Alice M Stewart, George W Kneale
}

\begin{abstract}
Objectives-To discover how the age when a given dose of ionising radiation is received (exposure age) affects the subsequent cancer risk, and whether the types of cancer caused by repeated exposure to small doses during adult life differ from naturally occurring cancers at that age. Method-A nested case-control design with all possible controls in a cohort of nuclear workers, and a Mantel-Haenszel test (requiring only one degree of freedom) to discover whether there was any level of exposure age where the null hypothesis of no effects of radiation was rejected. This analysis was followed by inspection of how different types of cancers were related to the cancer risk.

Results-For radiation received at least 15 years before a cancer death (to allow for cancer latency) evidence of a dose related risk was found which was largely the result of exposures during the last 10 years of working life (between 55 and 65 years of age). The relative frequency of site specific cancers showed no signs of being different for radiogenic and idiopathic cancers, and there was no evidence of the exceptionally strong association between radiation and leukaemia found in atomic bomb data and other high dose situations.

Conclusions-Sensitivity to carcinogenic effects of radiation increases progressively with age during adult life and, provided the dose is too small to produce many cell deaths, the ratio of leukaemias to solid tumours is no different for radiogenic and idiopathic cancers.
\end{abstract}

(Occup Environ Med 1996;53:225-230)

Department of Public Health and Epidemiology, University of Birmingham, Edgbaston, Birmingham B15 2TT A M Stewart $G \mathbb{W}$ Kneale

Correspondence to: Dr A M Stewart, Department of Public Health and Epidemiology, University of Birmingham, Edgbaston, Birmingham B15 2TT.

Accepted 27 November 1995
This choice of objectives was a direct consequence of two, independent analyses of exactly the same data coming to very different conclusions. Thus, according to Gilbert et al (whose method of statistical analysis made no allowance for any cancer modifying effects other than lag period)

"Updated analyses of mortality of workers at the Hanford site provide little evidence of a positive correlation with cumulative occupational radiation dose and mortality from leukaemia and from all cancer except leukaemia. Estimates of the excess relative risk per $10 \mathrm{mSv}$ are consistent both with no risk and with estimates obtained through extrapolation from high-dose data". ${ }^{1}$

But, according to Kneale and Stewart (whose analysis allowed for cancer modifying effects of three factors other than radiation dose)

"by a conservative estimate, about three per cent of the pre 1987 cancer deaths of Hanford workers had occupational exposures to external radiation as the critical (induction) event. These radiogenic cancers were evenly distributed between five diagnostic groups, but as a result of there being greater sensitivity to 'cancer induction by radiation' after than before 50 years of age, they were concentrated among the cancers which proved fatal after 70 years of age". 2

In the Gilbert et al analysis comparisons between the nuclear workers and national statistics (standardised mortality ratio (SMR) analysis) were followed by an attempt to estimate the excess relative risk with the personyear formulation of the Breslow and Day linear model of relative risk and observing the effect of different lag periods (ERR analysis). ${ }^{3}$ In the ERR analysis by Kneale and Stewart an alternative formulation of the Breslow and Day model was used-that is, the Cox risk set formulation, ${ }^{4}$ as this allowed modelling for any dependence of the cancer risk on factors such as the age when each annual dose of radiation was received (exposure age), the calendar year of each annual dose (exposure year), and the interval after exposure (cancer latency).

The two discordant analyses of Hanford data have since been followed by an analysis of pooled data from the United States, Canadian, and United Kingdom nuclear facilities. ${ }^{5}$ On this occasion the ERR analysis of Gilbert et al was used to show that the excess relative risk of leukaemia and other malignant neoplasms was not significantly different from estimates based on atomic bomb data. There was no attempt to discover how the numerous exposure ages of long term workers influenced the cancer risk, and no mention of any Kneale et al analyses of Hanford data. ${ }^{26}$ Hence the need for further tests of age related effects of radiation, bearing in mind how little is known about these effects in situations where there 
Table 1 Specifications of 2054 cancer cases

\begin{tabular}{|c|c|c|c|c|}
\hline \multirow[b]{2}{*}{ Specifications } & \multicolumn{4}{|c|}{ Cancer cases } \\
\hline & $A$ & $B$ & Total & $B(\%)$ \\
\hline \multicolumn{5}{|l|}{ Birth dates: } \\
\hline $1875-89$ & 50 & 14 & 64 & $21 \cdot 9$ \\
\hline $1890-99$ & 220 & 43 & 263 & $16 \cdot 3$ \\
\hline $1900-09$ & 517 & 60 & 577 & $10 \cdot 4$ \\
\hline 1910-19 & 656 & 54 & 710 & $7 \cdot 6$ \\
\hline $1920-29$ & 312 & 15 & 327 & $4 \cdot 6$ \\
\hline $1930-39$ & 85 & 5 & $90\}$ & 4.4 \\
\hline $1940+$ & 23 & & $23 \int$ & \\
\hline \multicolumn{5}{|l|}{ Death dates: } \\
\hline $\begin{array}{l}1944-59 \\
1960-64\end{array}$ & $\begin{array}{l}152 \\
122\end{array}$ & $\begin{array}{r}3 \\
11\end{array}$ & $\left.\begin{array}{l}155 \\
133\end{array}\right\}$ & $4 \cdot 9$ \\
\hline $1965-69$ & 205 & 17 & 202 & $8 \cdot 4$ \\
\hline $1970-74$ & 272 & 34 & 306 & $11 \cdot 1$ \\
\hline $1975-79$ & 360 & 42 & 402 & $10 \cdot 4$ \\
\hline $1980-84$ & 449 & 56 & 505 & $11 \cdot 1$ \\
\hline $1985-89^{\star}$ & 323 & 28 & 351 & $8 \cdot 0$ \\
\hline \multicolumn{5}{|l|}{ Cancers sites (ICD No): } \\
\hline Digestive (150-159) & 484 & 45 & 529 & $8 \cdot 5$ \\
\hline Respiratory (160-163) & 581 & 49 & 630 & $7 \cdot 8$ \\
\hline Genitourinary (180-189) & 242 & 54 & 296 & $18 \cdot 2$ \\
\hline Neoplasms of the reticuloendothelial & & & & \\
\hline system $(200-209)$ & 198 & 20 & 218 & $9 \cdot 2$ \\
\hline Other and unspecified & 358 & 23 & 381 & $6 \cdot 0$ \\
\hline Total & 1863 & 191 & 2054 & $9 \cdot 3$ \\
\hline
\end{tabular}

$\mathrm{A}=$ cases where cancer was the underlying cause of death; $\mathrm{B}=$ cases where cancer was a con tributory cause of a non-cancer death.

*Incomplete identification of death certificate data, mainly affecting deaths outside the State of Washington. are multiple exposures of the same person, and no question of cell killing effects of the radiation evoking the usual responses to life threatening situations.

\section{Materials and methods \\ BASIC ASSUMPTIONS AND METHODOLOGY}

In accordance with well established radiobiological principals, separate doses of radiation should act independently, and the total effect of several separate doses should equal the sum of each effect. Nevertheless, according to atomic bomb data (which describe the effects of a single exposure to a wide range of radiation doses) observable effects of the radiation were modified both by the age of the recipient (exposure age), and the duration of the period after exposure (cancer latency). ${ }^{8}$ It follows that, in situations where most of the people have repeated exposure to many small doses, the excess relative risk of cancer death at a particular point in time can only be accurately predicted as a weighted sum of the separate doses, with weights depending on the age when each component of a total individual dose is received, and the duration of each period after exposure.

In a cohort study of nuclear workers, this model of excess relative risk requires a statistical model the parameters of which can, in theory, be estimated by a standard statistical

Table 2 Recorded doses of 2045 cancer cases by interval before death

\begin{tabular}{|c|c|c|c|}
\hline \multirow[b]{2}{*}{ Interval before death $(y)$} & \multirow[b]{2}{*}{ Exposure age $(y)$} & \multicolumn{2}{|l|}{ Dose $(m S v)$} \\
\hline & & Total & Mean \\
\hline 0-14 (lag period) & All ages & 223081 & $108 \cdot 6$ \\
\hline $\begin{array}{l}\geqslant 15 \text { (excluding lag period): } \\
<35 \\
35-44 \\
45-54 \\
\geqslant 55 \\
\text { All ages }\end{array}$ & & $\begin{array}{rr}49 & 960 \\
108 & 650 \\
128 & 115 \\
834 & 268 \\
369 & 993\end{array}$ & $\begin{array}{r}24 \cdot 3 \\
52 \cdot 9 \\
62 \cdot 4 \\
40 \cdot 5 \\
180 \cdot 1\end{array}$ \\
\hline Total & All ages & 5931074 & $288 \cdot 7$ \\
\hline
\end{tabular}

package such as generalised linear models (GLIM). There are, however, many practical problems, including the fact that an individual worker could have 30 annual doses (each with a different exposure age and period after exposure) or 900 combinations of his or her total dose each with a separate weighting in the statistical model. This number could be reduced to 60 by assuming that each pair of exposure age dose weights and latency dose weights is a product of the two factors. But even so, the parameters would have to be further reduced by assuming specific parametric forms for 30 dose weights of age and 30 dose weights of latency.

In the 1993 analysis of Hanford data by Kneale and Stewart the parametric forms were step functions. In other words, for all exposure ages below a critical age (determined by the parameter) the dose weight was zero, and for all higher exposure ages there was a constant weight. The latency factor was treated in exactly the same way and thus was equivalent to the "dose lagging" procedures of Gilbert et al. ${ }^{1}$ However, the constraints of this model prevented consideration of more than one modifying factor, and the alternative model of Kneale and Stewart had no such constraints and produced both a critical value for minimal latency that was close to 15 years and a critical value for the youngest exposure age with any detectable effects of the radiation that was close to 60 years. Kneale and Stewart also showed that their second modifying factor (exposure age) was the principle reason why they found evidence of a dose related cancer risk-which was robust to a wide range of possible sources of error or confounding-and Gilbert et al failed to do so. ${ }^{2}$

The Kneale and Stewart findings for exposure age have not gained wide acceptance, possibly because they conflict with official interpretations of atomic bomb data. ${ }^{9}$ Hence, the present attempt to show that, if there is earlier expectation that the minimum cancer latency is close to 15 years, and that the cancer induction risk is different during early and late phases of adult life, then a relatively simple analysis of Hanford data would allow one to see the part played by exposure age in the cancer risks of nuclear workers and other people repeatedly exposed to low doses of ionising radiation.

MATERIALS AND STATISTICAL ANALYSIS

The Hanford data have already been described. ${ }^{2}$ They include records of 35868 badge monitored workers (mostly men) whose employment ages ranged from 18 to 65 years, and whose employment periods ranged from less than one to more than 30 years; and for each worker there was a set of annual doses of external penetrating radiation compiled from daily or weekly doses recorded on film badges. The mean annual dose rate was less than $1 \mathrm{mSv}$, and there were only 18 times when the maximal permissible dose of $50 \mathrm{mSv}$ per annum was exceeded. For the period 1944-78 the total cumulative dose was $831 \mathrm{~Sv}$, and for the period 1944-89 the number of ascertained deaths was 7874 . For 1863 of these deaths, 
Table 3 Cancer cases in 334 informative risk sets

\begin{tabular}{|c|c|c|c|c|c|c|c|c|c|c|c|c|}
\hline \multirow{2}{*}{$\begin{array}{l}\text { Final } \\
\text { years }\end{array}$} & \multicolumn{11}{|c|}{ Cancer cases by death ages $(y)$} & \multirow[b]{2}{*}{ Tota } \\
\hline & $<25$ & $<30$ & $<35$ & $<40$ & $<45$ & $<50$ & $<55$ & $<60$ & $<65$ & $<70$ & $\geqslant 75$ & \\
\hline 1944 & - & - & - & - & - & 1 & - & - & - & - & - & 1 \\
\hline 1945 & - & 1 & - & - & - & - & - & 1 & - & - & - & 2 \\
\hline 1946 & - & - & - & - & - & - & - & 1 & - & - & - & 1 \\
\hline 1947 & - & 1 & - & - & - & 1 & - & 1 & - & - & - & 3 \\
\hline 1948 & - & 1 & - & 1 & 1 & - & 1 & 1 & - & - & - & 5 \\
\hline 1949 & - & 1 & - & 1 & 1 & - & 2 & 2 & - & - & - & 7 \\
\hline 1950 & - & - & - & 1 & - & - & 1 & 3 & - & - & - & 5 \\
\hline 1951 & 1 & 1 & - & - & 1 & 4 & 1 & 1 & 2 & - & - & 11 \\
\hline 1952 & - & 1 & - & - & 1 & 2 & 3 & 1 & 1 & - & - & 9 \\
\hline 1953 & - & 1 & 1 & 2 & 3 & 2 & 3 & 3 & 1 & - & - & 16 \\
\hline 1954 & - & - & 2 & - & 1 & 2 & 3 & 1 & - & 3 & - & 12 \\
\hline 1955 & - & 2 & - & 1 & 1 & 2 & 1 & 4 & 1 & - & - & 12 \\
\hline 1956 & - & - & 1 & 1 & 2 & 1 & 2 & 1 & 4 & 1 & - & 13 \\
\hline 1957 & - & - & 1 & - & 2 & 3 & 5 & 2 & 1 & 2 & - & 16 \\
\hline 1958 & - & 1 & 1 & 4 & 3 & 2 & 1 & 4 & 4 & 1 & 1 & 22 \\
\hline 1959 & - & - & - & - & 5 & 3 & 3 & 4 & 2 & 2 & 1 & 20 \\
\hline 1960 & - & - & - & 2 & 1 & 3 & 3 & 4 & 5 & 2 & 2 & 22 \\
\hline 1961 & - & - & 4 & 4 & 1 & 1 & - & 4 & 5 & - & 3 & 22 \\
\hline 1962 & - & 1 & 2 & - & 4 & 4 & 6 & 1 & 5 & 4 & 2 & 29 \\
\hline 1963 & - & - & - & 1 & 1 & 3 & 7 & 10 & 6 & 2 & 1 & 31 \\
\hline 1964 & 1 & - & - & 2 & 5 & 1 & 3 & 7 & 5 & 4 & 1 & 29 \\
\hline 1965 & - & - & - & 2 & 2 & 4 & 4 & 6 & 7 & 8 & 2 & 35 \\
\hline 1966 & - & - & - & - & 1 & 4 & 6 & 3 & 2 & 4 & 6 & 26 \\
\hline 1967 & - & 1 & 3 & 1 & - & 7 & 11 & 6 & 7 & 4 & 2 & 42 \\
\hline 1968 & - & - & 2 & 4 & 2 & 1 & 7 & 11 & 11 & 3 & 2 & 43 \\
\hline $1969^{\star}$ & - & 1 & 2 & 1 & 4 & 3 & 8 & 10 & 12 & 12 & 3 & 56 \\
\hline 1970 & - & 1 & - & - & 4 & 10 & 12 & 8 & 10 & 4 & 8 & 57 \\
\hline 1971 & - & - & - & 2 & 1 & 8 & 14 & 13 & 9 & 11 & 9 & 67 \\
\hline 1972 & 1 & - & - & 2 & 3 & 4 & 8 & 13 & 10 & 7 & 10 & 58 \\
\hline 1973 & - & 1 & 1 & 3 & 4 & 7 & 6 & 12 & 12 & 8 & 8 & 62 \\
\hline 1974 & - & - & - & 2 & 2 & 10 & 9 & 9 & 7 & 7 & 16 & 62 \\
\hline 1975 & - & - & 2 & 1 & 3 & 4 & 12 & 15 & 13 & 8 & 9 & 67 \\
\hline 1976 & - & - & - & 2 & 2 & 7 & 6 & 24 & 9 & 16 & 14 & 80 \\
\hline 1977 & - & 3 & - & - & 1 & 9 & 7 & 17 & 9 & 16 & 16 & 78 \\
\hline 1978 & 1 & - & 1 & 3 & 3 & 6 & 10 & 19 & 16 & 13 & 17 & 89 \\
\hline 1979 & - & - & 2 & 3 & 6 & 4 & 7 & 16 & 17 & 15 & 18 & 88 \\
\hline 1980 & - & - & - & 1 & 2 & 7 & 15 & 14 & 21 & 21 & 21 & 102 \\
\hline 1981 & - & - & 1 & 2 & 2 & 3 & 7 & 12 & 29 & 16 & 14 & 86 \\
\hline 1982 & - & - & 1 & - & 3 & 2 & 19 & 9 & 22 & 16 & 29 & 101 \\
\hline 1983 & - & - & - & 2 & 4 & 3 & 10 & 11 & 34 & 15 & 24 & 103 \\
\hline 1984 & - & - & - & 3 & 2 & 4 & 11 & 17 & 25 & 21 & 30 & 113 \\
\hline 1985 & - & - & - & - & 3 & 2 & 12 & 13 & 21 & 19 & 32 & 102 \\
\hline 1986 & 1 & - & - & 2 & 5 & 6 & 7 & 11 & 11 & 22 & 37 & 102 \\
\hline 1987 & - & - & - & - & - & 3 & 3 & 11 & 9 & 14 & 20 & 60 \\
\hline 1988 & 1 & - & - & - & 1 & 2 & 4 & 3 & 8 & 10 & 17 & 46 \\
\hline 1989 & - & - & 1 & - & - & 2 & - & 4 & 10 & 8 & 16 & 41 \\
\hline Total & 6 & 18 & 28 & 56 & 93 & 157 & 260 & 343 & 383 & 319 & 391 & 2054 \\
\hline
\end{tabular}

cancer was the underlying cause, and for a further 191 deaths, cancer was a contributory cause (table 1). For the combined series of 2054 cancer related deaths the mean dose was $289 \mathrm{mSv}$, and for radiation received at least 15 years before death (prelag doses) the mean was $180 \mathrm{mSv}$ (table 2).

In the 1993 analysis of these data there were so many controlling factors that the number of informative risk sets (or risk sets containing one or more cancer cases) was only a fraction smaller than the total number of cancer cases, and there were no sets with more than five cases. $^{2}$ By having only the two controlling factors that are essential for any cohort analysis (date of birth and date of death), the number of informative risk sets was reduced to 334 , and there were 49 sets with more than a dozen cases (tables 3 and 4).

The number of cases and controls in the 334 informative risk sets ranged from 58 for one of the 10 sets whose final year was 1958 (one case and 57 controls), to 3770 for one of the eight sets whose final year was 1977 (nine cases and 3761 controls), and in four of the 32 sets with cancer related deaths after 74 years of age, there were more than 25 cases.

The much larger number of controls than cases in each risk set was the result of the Cox methodology making it necessary (a) to include, in each set of each final year, all the workers from a specific birth cohort who were still alive at the beginning of the final year, and (b) to restrict the cases to workers who recorded a cancer related death during this one year. ${ }^{4}$ With Hanford data in this formation we had the equivalent of a case-control study embedded in a cohort study. This meant that the likelihood function formula recommended by Breslow and Day for use in conventional case-control studies could be applied, since each of the 334 informative risk sets now corresponded to a single stratum in a MantelHaenszel analysis.

When it came to estimating the excess relative risk, the number and size of the informative risk sets threatened to create a computer storage problem. This was avoided with (as a test of the null hypothesis of no radiation effects) a later modification of the original Mantel-Haenszel procedures. ${ }^{10}$ With this Mantel method for testing trends of relative risk with increasing dose there is only one degree of freedom. Therefore, it was no longer necessary to store more than the mean doses of each risk set and their mean squares. This saving of computer space was important as, for each annual dose, we needed five separate components, one for lag period exposures, and four for age specific prelag exposures. 
Table 4 Matched controls of the cancer cases in table 3 and in 344 informative risk sets

\begin{tabular}{|c|c|c|c|c|c|c|c|c|c|c|c|}
\hline \multirow{2}{*}{$\begin{array}{l}\text { Final } \\
\text { years }\end{array}$} & \multicolumn{11}{|c|}{ Death ages of the cancer cases } \\
\hline & $<25$ & $<30$ & $<35$ & $<40$ & $<45$ & $<50$ & $<55$ & $<60$ & $<65$ & $<70$ & $\geqslant 75$ \\
\hline 1944 & - & - & - & - & - & 188 & - & - & - & - & - \\
\hline 1945 & - & 1324 & - & - & - & - & - & 104 & - & - & - \\
\hline 1946 & - & - & - & - & - & - & - & 136 & - & - & - \\
\hline 1947 & - & 1731 & - & - & - & 593 & - & 170 & - & - & - \\
\hline 1948 & - & 2030 & - & 1301 & 990 & - & 419 & 206 & - & - & - \\
\hline 1949 & - & 2107 & - & 1453 & 1116 & - & 476 & 240 & - & - & - \\
\hline 1950 & - & - & - & 1593 & - & - & 526 & 287 & - & - & - \\
\hline 1951 & 2504 & 2498 & - & - & 1254 & 1008 & 600 & 330 & 139 & - & - \\
\hline 1952 & - & 2654 & - & - & 1463 & 1050 & 691 & 376 & 165 & - & - \\
\hline 1953 & - & 2781 & 2656 & 2283 & 1596 & 1171 & 730 & 432 & 196 & - & - \\
\hline 1954 & - & - & 2727 & - & 1752 & 1288 & 801 & 484 & - & 78 & - \\
\hline 1955 & - & 3151 & - & 2644 & 1947 & 1244 & 1049 & 533 & 274 & - & - \\
\hline 1956 & - & - & 2977 & 2822 & 2127 & 1432 & 1071 & 593 & 311 & 128 & - \\
\hline 1957 & - & - & 3061 & - & 2348 & 1609 & 1118 & 671 & 341 & 150 & - \\
\hline 1958 & - & 3019 & 3164 & 2945 & 2500 & 1747 & 1238 & 711 & 384 & 176 & 57 \\
\hline 1959 & - & - & - & - & 2627 & 1852 & 1342 & 787 & 427 & 200 & 79 \\
\hline 1960 & - & - & - & 2981 & 2734 & 1986 & 1265 & 1022 & 473 & 233 & 93 \\
\hline 1961 & - & - & 3355 & 3084 & 2883 & 2112 & - & 1020 & 531 & - & 122 \\
\hline 1962 & - & 2696 & 3267 & - & 2915 & 2317 & 1571 & 1044 & 600 & 283 & 140 \\
\hline 1963 & - & - & - & 3289 & 2997 & 2476 & 1680 & 1156 & 610 & 312 & 176 \\
\hline 1964 & 1777 & - & - & 3436 & 3018 & 2609 & 1786 & 1243 & 678 & 348 & 196 \\
\hline 1965 & - & - & - & 3524 & 3045 & 2730 & 1926 & 1181 & 883 & 379 & 233 \\
\hline 1966 & - & - & - & - & 3156 & 2876 & 2062 & 1321 & 877 & 429 & 267 \\
\hline 1967 & - & 2169 & 2966 & 3443 & - & 2923 & 2259 & 1469 & 918 & 463 & 296 \\
\hline 1968 & - & - & 2793 & 3385 & 3386 & 3015 & 2417 & 1585 & 1017 & 489 & 322 \\
\hline $1969^{\star}$ & - & 2232 & 2579 & 3340 & 3539 & 3048 & 2548 & 1693 & 1089 & 551 & 357 \\
\hline 1970 & - & 2208 & - & - & 3623 & 3084 & 2667 & 1825 & 1041 & 722 & 408 \\
\hline 1971 & - & - & - & 3206 & 3625 & 3211 & 2818 & 1937 & 1156 & 711 & 467 \\
\hline 1972 & 1452 & - & - & 3099 & 3575 & 3295 & 2852 & 2122 & 1293 & 745 & 510 \\
\hline 1973 & - & 2004 & 2459 & 2942 & 3493 & 3428 & 2936 & 2271 & 1405 & 823 & 529 \\
\hline 1974 & - & - & - & 2823 & 3479 & 3613 & 2986 & 2416 & 1505 & 862 & 594 \\
\hline 1975 & - & - & 2658 & 2742 & 3458 & 3707 & 3054 & 2512 & 1636 & 844 & 760 \\
\hline 1976 & - & - & - & 2772 & 3475 & 3732 & 3216 & 2652 & 1749 & 967 & 781 \\
\hline 1977 & - & 2697 & - & - & 3457 & 3761 & 3360 & 2715 & 1916 & 1091 & 825 \\
\hline 1978 & 2740 & - & 2887 & 3075 & 3390 & 3745 & 3532 & 2817 & 2052 & 1216 & 909 \\
\hline 1979 & - & - & 2825 & 3080 & 3189 & 3709 & 3701 & 2864 & 2179 & 1308 & 1009 \\
\hline 1980 & - & - & - & 3098 & 3056 & 3646 & 3782 & 2957 & 2271 & 1410 & 1143 \\
\hline 1981 & - & - & 2846 & 3000 & 2999 & 3571 & 3763 & 3109 & 2423 & 1502 & 1254 \\
\hline 1982 & - & - & 2947 & - & 3013 & 3472 & 3713 & 3228 & 2483 & 1637 & 1403 \\
\hline 1983 & - & - & - & 2868 & 3042 & 3341 & 3638 & 3371 & 2578 & 1761 & 1554 \\
\hline 1984 & - & - & - & 2801 & 3049 & 3144 & 3606 & 3526 & 2634 & 1877 & 1686 \\
\hline 1985 & - & - & - & - & 3068 & 3024 & 3546 & 3584 & 2725 & 1966 & 1855 \\
\hline 1986 & 795 & - & - & 2823 & 2974 & 2959 & 3478 & 3565 & 2878 & 2096 & 2016 \\
\hline 1987 & - & - & - & - & - & 2966 & 3379 & 3534 & 2983 & 2168 & 2221 \\
\hline 1988 & 295 & - & - & - & 2846 & 3002 & 3258 & 3475 & 3149 & 2281 & 2530 \\
\hline 1989 & - & - & 2656 & - & - & 3017 & - & 3473 & 3306 & 2400 & 2840 \\
\hline
\end{tabular}

^See tables 5 and 6 .

All the controls in each final year have birth cohort in common with one another and with the cancer cases in table 3 .

\section{Results}

EXPOSURE AGE EFFECTS

With the cancer related deaths stretching from 1944-89, it was necessary to repeat 46 times simple hand calculations of observed and expected doses for five subdivisions of the total dose for each final year. Tables 5 and 6 only show the workings for one of these years, 1969 , with 56 cases and 10 risk sets. But this is sufficient to show each step of a process which allowed for latency effects by having two expo- sure periods (lag and prelag), and for exposure age effects by having four levels of age specificity for all prelag exposures $(<35 ; 35-44$, $45-54$ and $>55$ years).

In 1969 there were no cancer deaths before 30 years of age (table 3 ). This still left 10 sets of total and mean doses for the lag period, and 16 sets of total and mean doses for the prelag period (table 5). For example, in the set which included three cancer deaths after 75 years of age and 357 controls, there were the usual

Table 5 Total and mean doses ( $m S v$ ) for 10 informative risk sets (1969 cancer deaths)

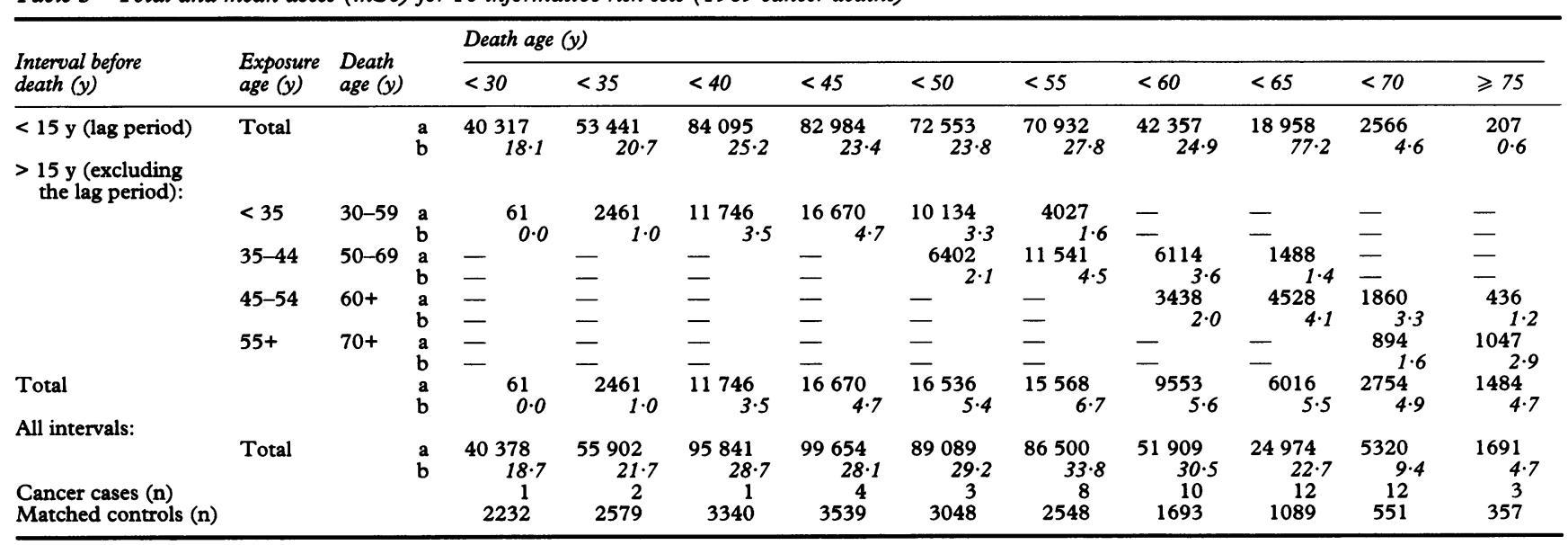

$a=$ Dose for all members of each informative risk set; $b=$ mean worker dose. 
Table 6 Observed and expected doses ( $m S v)$ for 10 informative risk sets (1969 cancer deaths)

\begin{tabular}{|c|c|c|c|c|c|c|c|c|c|c|c|c|c|c|c|}
\hline \multirow{2}{*}{$\begin{array}{l}\text { Interval before } \\
\text { death }(y)\end{array}$} & \multirow{2}{*}{$\begin{array}{l}\text { Exposure } \\
\text { age }(y)\end{array}$} & \multirow{2}{*}{\multicolumn{2}{|c|}{$\begin{array}{l}\text { Death } \\
\text { age }(y)\end{array}$}} & \multicolumn{10}{|c|}{ Death age $(y)$} & \multirow{2}{*}{$\begin{array}{l}\text { Total } \\
\text { dose }\end{array}$} & \multirow{2}{*}{$\begin{array}{l}\text { Ratio } \\
\text { O:E }\end{array}$} \\
\hline & & & & $<30$ & $<35$ & $<40$ & $<45$ & $<50$ & $<55$ & $<60$ & $<65$ & $<70$ & $\geqslant 75$ & & \\
\hline \multirow{2}{*}{$\begin{array}{l}<15 \text { y (lag period): } \\
>15 \text { y (excluding } \\
\text { the lag period): }\end{array}$} & Total & & $\stackrel{\mathrm{O}}{\mathrm{E}}$ & $\begin{array}{l}21 \\
18 \cdot 1\end{array}$ & $\begin{array}{l}61 \\
41 \cdot 4\end{array}$ & $\begin{array}{c}9 \\
25 \cdot 2\end{array}$ & $\begin{array}{l}83 \\
93 \cdot 6\end{array}$ & $\begin{array}{c}20 \\
71 \cdot 4\end{array}$ & $\begin{array}{l}157 \\
222 \cdot 4\end{array}$ & $\begin{array}{l}370 \\
249 \cdot 0\end{array}$ & $\begin{array}{c}176 \\
206 \cdot 4\end{array}$ & $\begin{array}{l}27 \\
55 \cdot 2\end{array}$ & $\begin{array}{l}0 \\
1 \cdot 8\end{array}$ & $\begin{array}{l}924 \\
984 \cdot 5\end{array}$ & 0.94 \\
\hline & $\begin{array}{l}<35 \\
35-44 \\
45-54 \\
\geqslant 55\end{array}$ & $\begin{array}{l}30-59 \\
50-69 \\
60+ \\
70+\end{array}$ & $\begin{array}{l}\mathbf{O} \\
\mathbf{E} \\
\mathbf{O} \\
\mathbf{E} \\
\mathbf{O} \\
\mathbf{E} \\
\mathbf{O} \\
\mathbf{E}\end{array}$ & $\begin{array}{l}- \\
0.0 \\
- \\
- \\
- \\
-\end{array}$ & $\begin{array}{l}- \\
2 \cdot 0 \\
- \\
- \\
- \\
-\end{array}$ & $\begin{array}{l}3 \\
3 \cdot 5 \\
- \\
- \\
- \\
- \\
-\end{array}$ & $\begin{array}{l}40 \\
18 \cdot 8 \\
- \\
- \\
- \\
- \\
-\end{array}$ & $\begin{array}{l}3 \\
9.9 \\
1 \\
\\
-6 \cdot 3 \\
- \\
-\end{array}$ & $\begin{array}{c}7 \\
12 \cdot 8 \\
41 \\
36 \cdot 0 \\
- \\
- \\
-\end{array}$ & $\begin{array}{l}- \\
- \\
25 \\
36 \cdot 0 \\
28 \\
20 \cdot 0 \\
-\end{array}$ & $\begin{array}{l}- \\
-13 \\
16 \cdot 8 \\
35 \\
49 \cdot 2 \\
-\end{array}$ & $\begin{array}{l}- \\
- \\
- \\
86 \\
39 \cdot 6 \\
27 \\
19 \cdot 2\end{array}$ & $\begin{array}{l}- \\
- \\
- \\
1 \\
3 \cdot 6 \\
10 \\
8.7\end{array}$ & $\begin{array}{l}53 \\
47 \cdot 0 \\
80 \\
95 \cdot 1 \\
150 \\
112 \cdot 4 \\
37 \\
27 \cdot 9\end{array}$ & $1 \cdot 13$ \\
\hline Total & & & $\begin{array}{l}\mathbf{O} \\
\mathbf{E}\end{array}$ & $\begin{array}{l}0 \\
0.0\end{array}$ & $\begin{array}{l}0 \\
2 \cdot 0\end{array}$ & $\begin{array}{l}3 \\
3 \cdot 5\end{array}$ & $\begin{array}{l}40 \\
18 \cdot 8\end{array}$ & $\begin{array}{c}4 \\
16 \cdot 2\end{array}$ & $\begin{array}{l}48 \\
48 \cdot 8\end{array}$ & $\begin{array}{l}53 \\
56 \cdot 0\end{array}$ & $\begin{array}{l}48 \\
66 \cdot 0\end{array}$ & $\begin{array}{l}113 \\
58 \cdot 8\end{array}$ & $\begin{array}{l}11 \\
12 \cdot 3\end{array}$ & $\begin{array}{l}320 \\
282 \cdot 4\end{array}$ & $1 \cdot 13$ \\
\hline Cancer cases (n) & Total & & $\underset{\mathbf{E}}{\mathbf{O}}$ & $\begin{array}{l}21 \\
18 \cdot 1 \\
1\end{array}$ & $\begin{array}{l}61 \\
43 \cdot 4 \\
2\end{array}$ & $\begin{array}{l}12 \\
28 \cdot 7 \\
1\end{array}$ & $\begin{array}{c}123 \\
112 \cdot 4 \\
4\end{array}$ & $\begin{array}{l}24 \\
87 \cdot 6 \\
3\end{array}$ & $\begin{array}{l}205 \\
270 \cdot 4 \\
8\end{array}$ & $\begin{array}{l}423 \\
305 \cdot 0 \\
10\end{array}$ & $\begin{array}{l}224 \\
272 \cdot 4 \\
12\end{array}$ & $\begin{array}{l}140 \\
112 \cdot 8 \\
12\end{array}$ & $\begin{array}{c}11 \\
14 \cdot 1 \\
3\end{array}$ & $\begin{array}{c}1244 \\
1264 \cdot 9 \\
56\end{array}$ & 0.98 \\
\hline
\end{tabular}

$\mathrm{O}=$ Observed doses for all cancers in each informative risk set; $\mathrm{E}=$ expected dose or mean worker dose times the number of cancer cases.

(four) choices of age for any prelag exposures, but there were no such exposures before 45 years. For the next 10 years of age (45-54) the total dose was $436 \mathrm{mSv}$ and the mean 0.8 $\mathrm{mSv}$, and for all later exposures the total dose was $1047 \mathrm{mSv}$ and the mean $2.9 \mathrm{mSv}$. Both for the 10 groups of lag period exposures, and for the 16 groups of prelag exposures we have (table 6) observed and expected doses for the cases, the expected being based on the relevant mean dose in table 5 . Thus, for the three cases over 74 years of age the observed doses were: zero for the lag period, $1 \mathrm{mSv}$ for prelag exposures before 55 years, and $10 \mathrm{mSv}$ for later prelag exposures, and the expected doses were $1.8,3 \cdot 6$, and $8.7 \mathrm{mSv}$.

Table 6 also shows the O:E ratios for the 56 cases under three headings: (a) all lag period and prelag exposures with a total dose of 1244 $\mathrm{mSv}$ and an expected dose of $1264.9 \mathrm{mSv}$ (ratio 0.98); (b) lag period exposures only, with a total dose of $924 \mathrm{mSv}$ and an expected dose of $984.5 \mathrm{mSv}$ (ratio 0.94), and (c) prelag exposures only, with a total dose of $320 \mathrm{mSv}$ and an expected dose of $282.4 \mathrm{mSv}$ (ratio $1 \cdot 13)$. Finally, for the four groups of age specific prelag doses the O:E ratios were $1 \cdot 13$ (<35 years); 0.84 (35-44 years); and 1.33 (45-54 and $>55$ years).

Table 7 Observed and expected doses for ascertained cancers in three follow up periods

\begin{tabular}{|c|c|c|c|c|c|}
\hline \multirow{2}{*}{$\begin{array}{l}\text { Follow up period } \\
\text { (ascercained cancers) }\end{array}$} & \multirow{2}{*}{$\begin{array}{l}\text { Exposure } \\
\text { period }\end{array}$} & \multirow{2}{*}{$\begin{array}{l}\text { Exposure } \\
\text { age } \\
(y)\end{array}$} & \multicolumn{2}{|c|}{ Dose $(m S v)$} & \multirow{2}{*}{$\begin{array}{l}\text { Ratio } \\
O: E\end{array}$} \\
\hline & & & $O$ & $E$ & \\
\hline \multirow[t]{5}{*}{$1944-74(796)$} & All & \multirow{17}{*}{$\begin{array}{l}\text { all ages } \\
\text { all ages } \\
<35 \\
35-44 \\
45-54 \\
\geqslant 55 \\
\text { all ages } \\
\text { all ages } \\
<35 \\
35-44 \\
45-54 \\
\geqslant 55 \\
\text { all ages } \\
\text { all ages } \\
<35 \\
35-44 \\
45-54 \\
\geqslant 55\end{array}$} & 13975 & 14921 & 0.94 \\
\hline & Lag & & 10234 & 11602 & $0 \cdot 88$ \\
\hline & & & 642 & 696 & 0.92 \\
\hline & Prelag & & $\begin{array}{l}1477 \\
1121\end{array}$ & $\begin{array}{l}1221 \\
1028\end{array}$ & $\begin{array}{l}1.21 \\
1.09\end{array}$ \\
\hline & & & 501 & 374 & $1 \cdot 34$ \\
\hline \multirow[t]{4}{*}{$1944-84(1703)$} & All & & 40441 & 47223 & $0 \cdot 86$ \\
\hline & $\begin{array}{l}\text { Lag } \\
\text { Prelag }\end{array}$ & & $\begin{array}{r}19631 \\
2929\end{array}$ & $\begin{array}{r}26546 \\
3305\end{array}$ & $\begin{array}{l}0.74 \\
0.89\end{array}$ \\
\hline & & & 6694 & 6581 & $1 \cdot 02$ \\
\hline & & & $\begin{array}{l}6917 \\
4270\end{array}$ & $\begin{array}{l}7875 \\
2916\end{array}$ & $\begin{array}{l}0.88 \\
1.46\end{array}$ \\
\hline \multirow[t]{5}{*}{$1944-89(2054)$} & All & & 59292 & 58816 & 1.01 \\
\hline & Lag & & 22362 & 28513 & 0.78 \\
\hline & Prelag & & 4996 & 4709 & 1.06 \\
\hline & & & 10803 & 9409 & $1 \cdot 15$ \\
\hline & & & 12810 & 11519 & 1.11 \\
\hline \multirow{3}{*}{ Prelag exposures all ages } & & & $\begin{array}{r}8321 \\
374\end{array}$ & $\begin{array}{l}4000 \\
3319\end{array}$ & 1.13 \\
\hline & $1944-84$ & & 20810 & 20677 & 1.01 \\
\hline & $1944-89$ & & 36930 & 30303 & $1 \cdot 22$ \\
\hline
\end{tabular}

Abbreviations as in table 6 .
For the complete series of 2054 cancer cases (with 334 risk sets distributed between 46 final years) the $\mathrm{O}: \mathrm{E}$ ratios were 1.01 for all exposures (total dose of $59292 \mathrm{mSv}$ ), 0.78 for the lag period exposures (total dose of 22362 $\mathrm{mSv}$ ), and 1.22 for the remaining, prelag exposures (total dose of $36930 \mathrm{mSv}$, table 7). For four groups of age specific prelag doses the ratios were 1.06 ( $<35$ years); 1.15 (35-45 years); $1 \cdot 11$ ( $45-54$ years), and 1.78 ( $>55$ years).

Table 7 also shows how the findings for the total follow up period (1944-89) compare with two shorter periods, 1944-75 with 796 cancer cases in 235 risk sets, and 1944-84 with 1703 cases in 298 risk sets. For each follow up period the O:E ratio was higher for prelag than lag period doses, and higher for prelag exposures after 55 years of age than for earlier exposures. But it was not until the follow up period exceeded 40 years that all $\mathrm{O}: \mathrm{E}$ ratios for prelag exposures were greater than $1 \cdot 0$. For prelag exposures with the highest O:E ratio $(1.78)$ the observed and expected dose were 8321 and $4666 \mathrm{mSv}$. According to the $\chi^{2}$ test of Mantel ${ }^{10}$ this is a highly significant difference $(P<0.0001)$. Therefore, despite the need for separate consideration of five components of each total dose, a remarkably simple analysis has provided strong support for an earlier conclusion of Kneale and Stewart, namely, that the cancer risk after exposure to radiation is much greater for exposures after than before 50 years of age. But also note that with the Gilbert et al model (which only incorporates lag or latency effects) we would have been left with $36930 \mathrm{mSv}$ as the observed dose and 30303 for the expected dose, and an O:E ratio of $1 \cdot 22$, which was only of doubtful significance.

TWO TYPES OF RADIOGENIC CANCER

Although there has never been any suggestion of a special relation between leukaemia and radiation either in the Hanford data or in studies of carcinogenic effects of prenatal $x$ ray films, ${ }^{11}$ uniform ERRs for several types of adult cancer are relatively recent findings. ${ }^{2}$ Therefore, in table 8, the cancer cases whose prelag doses for exposures after 55 years of age were 
Table 8 Comparisons between all cancer cases and the high risk cases in five diagnostic groups

\begin{tabular}{|c|c|c|c|c|c|c|}
\hline \multirow[b]{2}{*}{ Types of cancer } & \multicolumn{3}{|c|}{ High risk cancers * } & \multicolumn{3}{|c|}{ Other cancers } \\
\hline & $\begin{array}{l}\text { All cases } \\
n\end{array}$ & $\begin{array}{l}B \text { seriest } \\
n\end{array}$ & $(\%)$ & $\begin{array}{l}\text { All cases } \\
n\end{array}$ & $\begin{array}{l}B \text { seriest } \\
n\end{array}$ & $(\%)$ \\
\hline $\begin{array}{l}\text { Digestive } \\
\text { Respiratory } \\
\text { Prostate } \\
\text { Other genitourinary } \\
\text { Neoplasms of the }\end{array}$ & $\begin{array}{l}32 \\
50 \\
24 \\
12\end{array}$ & $\begin{array}{l}7 \\
8 \\
9 \\
2\end{array}$ & $\begin{array}{l}21 \cdot 9 \\
16 \cdot 0 \\
37 \cdot 5 \\
16 \cdot 7\end{array}$ & $\begin{array}{l}497 \\
580 \\
146 \\
114\end{array}$ & $\begin{array}{l}38 \\
41 \\
29 \\
14\end{array}$ & $\begin{array}{r}7 \cdot 6 \\
7 \cdot 1 \\
19 \cdot 9 \\
12 \cdot 3\end{array}$ \\
\hline $\begin{array}{l}\text { reticuloenothelial system } \\
\text { Other and unspecified }\end{array}$ & $\begin{array}{l}16 \\
29\end{array}$ & $\begin{array}{l}2 \\
5\end{array}$ & $\begin{array}{l}12 \cdot 5 \\
34 \cdot 5\end{array}$ & $\begin{array}{l}202 \\
352\end{array}$ & $\begin{array}{l}18 \\
18\end{array}$ & $\begin{array}{l}8 \cdot 9 \\
5 \cdot 1\end{array}$ \\
\hline Total & 163 & 33 & $20 \cdot 2$ & 1891 & 158 & $8 \cdot 4$ \\
\hline
\end{tabular}

${ }^{\star}$ Cancers with doses from prelag exposures after 55 years of age that exceeded the expected dose; tsee footnote to table 1 greater than the expected dose (163 high risk cases) are compared with the remaining 1891 cases, after division of each group into six diagnostic categories and separate identification of the cancers that were only contributory causes of death (B series, as in table 1).

In the high risk group $100 \%$ of the deaths occurred after 75 years of age, and in the comparison group the corresponding proportion was only $12 \%$. In both series the dominant disease was lung cancer (31\%) but in the high risk subset there was better representation of cancers with exceptionally late death ages (prostate tumours) than in the comparison group, and in the B series of high risk cancers almost a quarter of the cases were prostate tumours. In short, apart from a tendency for cancers with late death ages to concentrate in a series which was, by definition, restricted to deaths after 70 years of age, there were no detectable differences between these elderly cases and the remaining 1891 deaths related to cancer. And the proportion of leukaemias and other reticuloendothelial system neoplasms was certainly no higher for the high risk cases $(10 \%)$ than the other cases $(11 \%)$.

\section{Discussion}

People who are approaching the end of the life span are exceptionally sensitive to all causes of death. Therefore, the idea that old people are less sensitive to carcinogenic effects of radiation than young adults is totally out of line with normal experience. This common assumption is the result of the Radiation Effects Research Foundation (RERF) both finding a lower excess relative risk for atomic bomb survivors who were over 50 years of age in 1945 than for younger people, ${ }^{9}$ and insisting that "the survivors, apart from their radiation, are representative human beings". ${ }^{12}$ From atomic bomb data has also come the idea that radiation is more likely to cause leukaemia than other cancers, and the idea that there were no lasting effects of the tissue damage caused by cell deaths from radiation. ${ }^{1314}$

Numerous tests of the RERF assumptions have satisfied radiation protection committees. ${ }^{8}$ However, an independent analysis of atomic bomb data recently found both evidence of selection effects of deaths before $1950^{15}$ and evidence of late effects of marrow damage. ${ }^{16}$ Furthermore, according to Stewart-who has long suspected that the exceptionally high death rate for aplastic anaemia in the life span study cohort was the result of irreversible damage to the reticuloendothelial system ${ }^{17}$-the special association between leukaemia and radiation in atomic bomb data could easily be the result of a life saving leucocytosis leaving survivors at high risk of an early death from leukaemia caused by excessive numbers of mutant myelocytes and cancer promoter effects of damage to the reticuloendothelial system. ${ }^{7}$

Even without this last conjecture there are strong grounds for thinking that any holocaust would leave an indelible mark on a closed population of survivors, such as the life span study cohort, and that there are no exceptions to the rule that sensitivity to all causes of death relentlessly increases with age during adult life. Therefore, although the present findings of a relation between radiation effects and exposure age are at variance with official interpretations of atomic bomb data, this should not be regarded as a reason for doubting that middle aged and elderly workers are far more sensitive to effects of radiation in the induction of cancer than young recruits. Nor is it unreasonable to suggest that cell killing as well as mutational effects of the atomic bomb radiation contributed to the high death rate from myeloid leukaemia in the life span study cohort.

We are indebted to the Three Mile Island Public Health Fund for obtaining the data we have examined and defraying the full cost of the analysis.

1 Gilbert ES, Omohundro E, Buchanan JA, Hotter NA Mortality of workers at the Hanford site: 1945-86. Health Phys 1993;64:577-90.

2 Kneale GW, Stewart AM. Reanalysis of Hanford data: 1944-86 deaths. Am 7 Ind Med 1993;23:371-89.

3 Breslow NE, Day NE. Statistical methods in cancer research. Vol II. Lyons: International Agency for Research on Cancer, 1980.

4 Cox DR. Regression models in life tables. Fournal of the Royal Statistical Society B 1972;34:187-220.

5 Cardis E, Gilbert ES, Carpenter L, Howe G, Kato I, Armstrong BK, et al. Effects of low doses and low dose rates of external ionizing radiation: cancer mortality among nuclear workers in three countries. Radiat Res 1995;142:117-32.

6 Stewart AM, Kneale GW. An overview of the Hanford controversy. Occupational Medicine: State of the Art Review troversy. Occupan

7 Stewart AM. Relative sensitivity of myeloid and lymphatic stem cells to mutational and cell killing effects of ionizing

8 BEIR V. Health effects of exposure to low levels of ionizing radiation. Washington, DC: National Academy Press, 1990.

9 Preston D, Kato H, Kopecky KJ, Fujita S. Studies of the mortality of A-bomb survivors: 8 Cancer mortality, 1950-82. Radiat Res 1987;111:151-78.

10 Mantel N. Chi-square tests with one degree of freedom. Extensions of the Mantel-Haenszel procedures. Fournal of the American Statistical Association 1963;58:690-701.

11 Knox EG, Stewart AM, Kneale GW, Gilman E. Prenata irradiation and childhood cancer. Fournal of Radiological irradiation and childho

12 Minutes of a meeting of the Radiation Effects Research Foundation (RERF) Scientific Committee on March Foundation (

13 Beebe GW, Kato H, Land CE. The hypothesis of radiation-accelerated ageing and the mortality of Japanese Abomb victims. In: Late Radiological Effects of Ionizing Radiation 1978;1:3-18

14 Ohkita T. Acute effects. In: A review of thirty years study of Hiroshima and Nagasaki atomic bomb survivors. fournal of Radiation Research 1975;8uppl: 49-66.

15 Stewart AM, Kneale GW. A-bomb survivors: further evidence of late effects of early deaths. Health Phys 1993; 64:467-72.

16 Stewart AM, Kneale GW. A-bomb radiation and evidence of late effects other than cancer. Health Phys 1990;58: 729-35.

17 Stewart AM. Delayed effects of A-bomb radiation: a review of recent mortality rates and risk estimates for five-year survivors. $尹$ Epidemiol Community Health 1982;36:80-6. 